\title{
Kajian Struktur Ukuran Dan Parametr Populasi \\ Kepiting Bakau (Scylla serrata) di Ekosistem Mangrove Teluk Bintan, Kepulauan Riau
}

\section{Study Of Size Structure And Population Mud Crab (Scylla serrata) In Mangrove Ecosystem Bintan Gulf, Riau Islands}

\author{
M. Tahmid ${ }^{1 *}$, Achmad Fahrudin ${ }^{2}$, Yusli Wardiatno ${ }^{2}$ \\ ${ }^{1}$ MProgram Studi Pengelolaan Sumberdaya Persisir dan Laut, Sekolah Pascasarjana, Institut \\ Pertanian Bogor, Kampus Darmaga, Bogor 16680 \\ ${ }^{2}$ Departemen Manajemen Sumberdaya Perairan, Fakultas Perikanan dan Ilmu Kelautan, \\ Institut Pertanian Bogor (IPB) \\ *E-mail: mrtahmid.mt@gmail.com
}

\begin{abstract}
ABSTRAK
Kepiting bakau (Scylla serrata) merupakan salah satu potensi komoditas perikanan skala kecil yang memiliki nilai ekonomi tinggi. Kelimpahan populasi dipengaruhi oleh upaya penangkapan dan kondisi ekosistem mangrove sebagai habitat utamanya. Produksi kepiting bakau di Teluk Bintan menurun dan penyebabnya belum diketahui dengan pasti. Oleh karena itu, perlu dilakukan kajian tentang biologi kepiting bakau di Teluk Bintan. Penelitian ini bertujuan untuk mengkaji status populasi kepiting bakau yang meliputi struktur ukuran, parameter pertumbuhan dan laju mortalitas dan eksploitasi. Pengambilan data kepiting bakau dilakukan dengan pendekatan yaitu fisher-based survey. Hasil penelitian menunjukkan ukuran kepiting bakau yang tertangkap mulai dari lebar karapas (CW) 64-172 mm, ukuran fase muda kepiting jantan yang tertangkap mencapai 46,62\% dan betina mencapai $48,06 \%$, keduanya hampir setengah dari tangkapan total, ini menunjukkan bahwa alat tangkap yang digunakan belum selektif. $\mathrm{CW} \infty$ jantan mencapai $176,93 \mathrm{~mm}$ lebih tinggi dari kepiting betina sebesar $169,58 \mathrm{~mm}$, namun sebaliknya nilai koefesien $\mathrm{K}$ jantan $(0,360)$ lebih kecil dari betina $(0,390)$, sehingga pertumbuhan kepiting bakau betina lebih cepat dari jantan. Perkiraan angka kematian alami (M) jantan $=0,5566$ dan kematian akibat penangkapan $(F)$ jantan $=0,6434$ sedangkan $\mathrm{M}$ betina $=0,59$ dan $\mathrm{F}$ betina $=0,41$. Laju eksploitasi (E) kepiting jantan mencapai 53,62\%, ini dapat dikatakan telah terjadi lebih tangkap atau over eksploitasi.
\end{abstract}

Kata kunci: Scylla serrata, parameter pertumbuhan, struktur ukuran, mangrove and Teluk Bintan

\begin{abstract}
Mud crab (Scylla serrata) is one of the potential of small-scale fishery commodities that have high economic value. The abundance of the population is affected by the fishing effort and conditions mangrove ecosystem as its main habitat. Mud crab production in the Gulf of Bintan declined and the cause is not known with certainty. Therefore, it is necessary to study on the biology of mud crab in the Gulf of Bintan. This study aims to assess the status of mangrove crab population that includes the size structure, parameters of growth and the rate of mortality and exploitation. Data retrieval is done with a mangrove crab fisher-based survey. The results showed that the size of mud crab caught from carapace width $(\mathrm{CW})$ 64-172 $\mathrm{mm}$, the size of the young phase male crabs caught females reached $46.62 \%$ and reached $48.06 \%$, both are almost half of the total catch, it indicates that fishing gear used is not selective. $C W \infty$ males reach $176.93 \mathrm{~mm}$ higher than the female crabs of $169.58 \mathrm{~mm}$, but instead value koefesien $K$ males (0.360) is smaller than females (0.390), so that the growth of female mud crabs faster than males. Estimated natural mortality rates $(M)$ male $=0.5566$ and deaths from arrest $(F)$ male $=0.6434$ while $M$ females female $F=0.59$ and $=0.41$. The rate of exploitation $(E)$ male crabs reached $53.62 \%$, can be said to have occurred over fishing or over-exploitation.
\end{abstract}

Keywords: Scylla serrata, growth parameters, structure size, mangrove and bay Bintan 


\section{PENDAHULUAN}

Kepiting bakau (Scylla spp) merupakan salah satu potensi komoditas perikanan yang mempunyai nilai ekonomis tinggi (Laroso et al. 2013). Di Indonesia, spesies ini tersebar luas dari barat (Sumatera) ke timur (Papua) yang tersebar di banyak wilayah pesisir yang memiliki hutan mangrove yang luas dan perairan estuari dan kegiatan penangkapan terhadap sumberdaya kepiting bakau trend eksploitasinya menunjukkan peningkatan (La Sara (2010). Permintaan kepiting bakau di Pulau Bintan yaitu untuk memenuhi permintaan pasar lokal antara lain hotel, restoran seafood dan pasar ekspor. Karena permintaan lokal dan ekspor semakin meningkat, secara langsung menyebabkan upaya untuk memenuhi kebutuhan pasar semakin meningkat dan berdampak terhadap meningkatnya upaya penangkapan kepiting bakau. Menurut Mirera (2011); Dumas et al. (2012), meningkatnya permintaan pasar lokal dan global telah menyebabkan eksploitasi berlebihan dari alam yang terlihat dari penurunan hasil tangkapan dan penurunan rata-rata ukuran yang tertangkap.

Mangrove di Kabupaten Bintan kurang lebih seluas 7.972,21 hektar dan sebagian besar berada di pesisir Teluk Bintan dengan luas $\pm 1.463,97$ hektar (ITTO Project 2013) yang terdistribusi di sepanjang pesisir pantai dan daerah aliran sungai. Keberadaan mangrove tersebut oleh masyarakat lokal secara langsung dijadikan sebagai sumber mata pencaharian baik berupa sumberdaya hutan mangrove maupun sumber daya perikanan, sehingga kawasan tersebut memiliki potensi dan peranan penting sebagai penyangga kehidupan masyarakat. Salah satu potensi perikanan dari ekosistem mangrove Teluk Bintan yang telah dimanfaatakan secara terus menerus oleh masyarakat adalah sumberdaya kepiting bakau (Scylla serrata).

Populasi kepiting bakau secara khas berasosiasi dengan hutan mangrove yang masih baik. Sehingga terdegradasinya habitat akan memberikan dampak yang serius terhadap keberadaan populasi kepiting bakau di alam (Le Vay 2001). Menurut nelayan setempat hasil tangkapan kepiting bakau 10 tahun terahir semakin menurun dan penyebabnya belum diketahui dengan pasti apakah dipengaruhi oleh over fishing atau kerusakan habitat. Untuk itu diperlukan pengelolaan dengan benar agar pemanfaatannya dapat berkelanjutan. Untuk melakukan pengelolaan perikanan yang rasional harus dilakukan monitor terhadap keadaan populasi dalam waktu tertentu seperti mempelajari parameter populasi (Effendie 2006).

Penelitian ini bertujuan untuk mengkaji status populasi kepiting bakau (Scylla serrata) yang meliputi struktur ukuran, parameter pertubuhan, laju mortalitas dan eksploitasi di lokasi penelitian. Hasil kajian ini diharapkan dapat digunakan sebagai bahan pertimbangan dalam pengelolaan Scylla serrata di ekosistem mangrove Teluk Bintan agar dapat dimanfaatan secara berkelanjutan.

\section{BAHAN DAN METODE}

\subsection{Lokasi dan Waktu Penelitian}

Penelitian ini dilaksanakan di kawasan mangrove Teluk Bintan Kabupaten Bintan yang terletak terletak antara $0^{0} 6^{\prime} 17^{\prime \prime}$ - $1^{0} 34^{\prime} 52^{\prime \prime}$ Lintang Utara dan $104^{\circ} 12^{\prime} 47^{\prime \prime}$ Bujur Timur disebelah Barat - 108 2 '27' Bujur Timur di sebelah Timur (Gambar 1). Penelitian ini dilaksanakan selama 4 bulan dari bulan Februari - Mei 2015. Lokasi sampling kepiting dikelompokkan berdasarkan lokasi penangkapan nelayan terdiri dari tiga kawasan yaitu Tembeling dengan luas mangrove $\pm 785,12$ ha, Bintan Buyu dengan luas $\pm 136,50$ ha dan Penaga dengan luas mangrove 432,59 ha (ITTO Project 2013).

\subsection{Metode Pengumpulan Data}

Data yang digunakan dalam penelitian ini adalah data primer, berupa data biologi kepiting bakau (Scylla serrata). Pengumpulan data dilakukan dengan pendekatan fisher-based survey mengunakan hasil tangkapan nelayan (Dumas et al. 2012). Data kepiting terdiri dari data lebar karapas (Carapace Width/CW), bobot badan dan jenis kelamin dan lokasi penangakapan. 


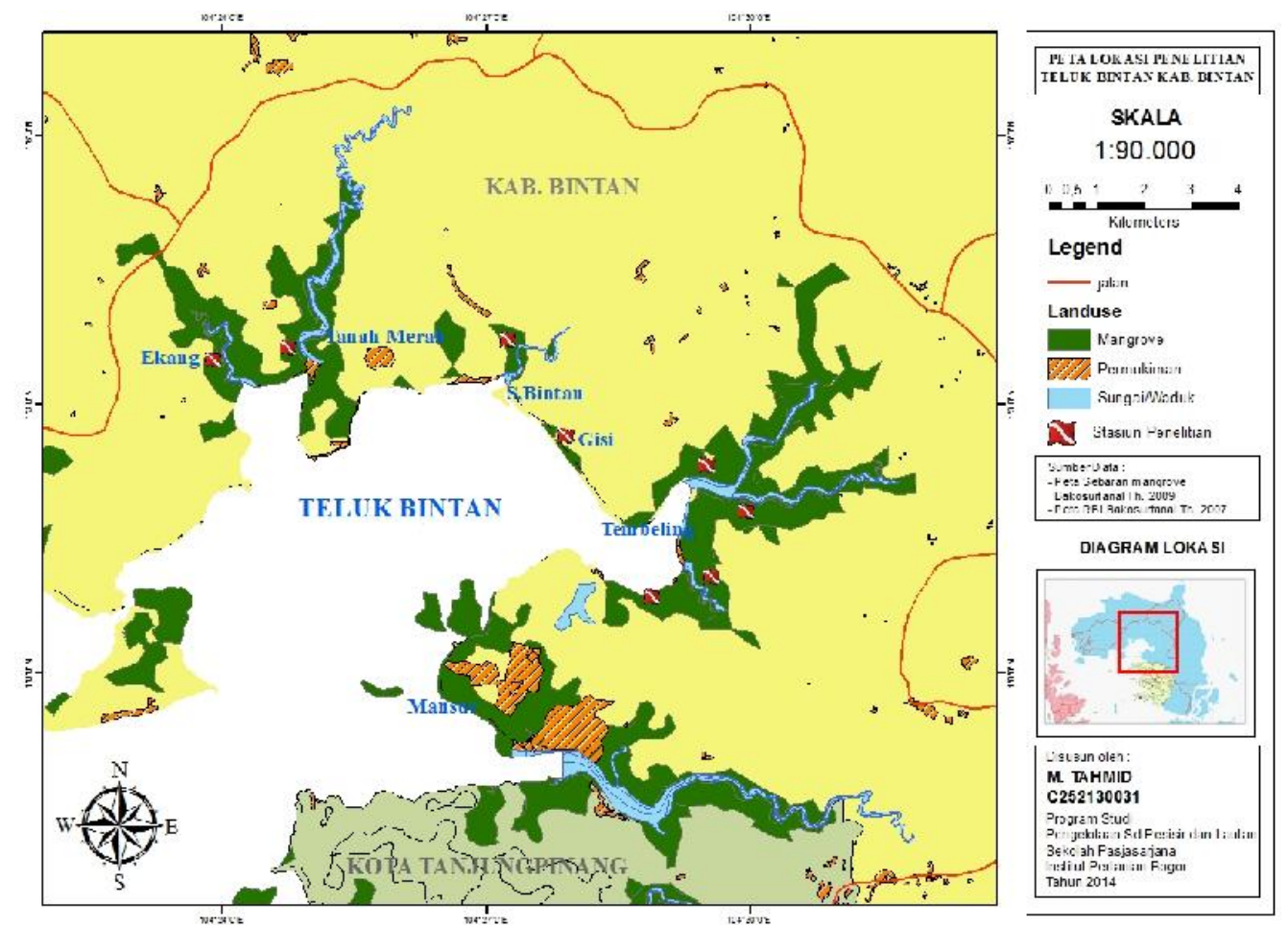

Gambar 1 Lokasi Penelitian

$$
\mathrm{C}_{\mathrm{t}}=\mathrm{CW} \infty\left(1-\mathrm{e}^{[-\mathrm{K}(\mathrm{t}-\mathrm{t} 0)]}\right)
$$

\subsection{Analisis Status Biologi Kepiting Bakau}

Data hasil tangkapan nelayan dari lokasi penelitian yang dianalisis meliputi Struktur ukuran, hubungan panjang bobot, parameter pertumbuhan $(\mathrm{CW} \infty, \mathrm{K})$, mortalitas total $(\mathrm{Z})$, mortalitas alami (M), laju penangkapan (F) dan tingkat eksploitasi (E). Struktur ukuran dari kedua jenis kelamin dianalisis distribusi frekuensi CW, tabulasi upaya tangkap dan hasil tangkapan untuk memprediksi total produksi tangkapan di lokasi penelitian.

Hubungan Panjang bobot digunakan untuk menggambarkan pola pertumbuhan kepiting bakau dalam dua bentuk yaitu isometrik negatif dan allometrik dengan menggunakan persamaan Hile (Effendie 2006) yaitu :

$\mathrm{W}=\mathrm{a} \mathrm{L}^{\mathrm{b}}$

dimana $\mathrm{W}$ adalah bobot tubuh (gram), L adalah lebar karapas (mm) (Carapace Width/CW), a dan $\mathrm{b}$ adalah konstanta yang diperoleh dari hasil analisis regresi dengan $\mathrm{Ln} \mathrm{W}$ sebagai $\mathrm{Y}$ dan $\mathrm{Ln} \mathrm{L}$ sebagai X.

Pendugaan parameter pertumbuhan dilakukan dengan persamaan von Bertalanffy: dimana Ct adalah Lebar karapas kepiting pada saat umur t (satuan waktu), $\mathrm{CW} \infty$ adalah Lebar maksimun karapas secara teoritis (panjang asimtotik), $\mathrm{K}$ adalah Koefisien pertumbuhan (per satuan waktu), $t_{0}$ adalah umur teoritis pada saat panjang sama dengan nol. Nilai $\mathrm{CW}_{\infty}$ dan $\mathrm{K}$ dihitung dengan metode ELEFAN I (Electronic Length Frequencys Analisis) dalam program FISAT II. Untuk menetukan $\mathrm{t}_{0}$ (umur teoritis) kepiting pada saat lebar karapas sama dengan nol dihitung secara terpisah menggunakan persamaan empiris Pauly sebagai berikut :

$\log (-\mathrm{t} 0)=0.3922-0.2752 \log \mathrm{L} \infty-1.038 \log \mathrm{K}$.

Setelah parameter pertumbuhan diketahui maka dilakukan pendugaan laju mortalitas total (Z) dan mortalitas alami (M). M diduga dengan menggunakan rumus empiris Pauly sebagai berikut:

$\log \mathrm{M}=0.0066-0.279 * \log \mathrm{L} \infty+0.6543 * \log \mathrm{K}+$ $0.4634 * \log \mathrm{T}$

dimana $\mathrm{T}$ adalah temperatur perairan. Nilai $\mathrm{Z}$ dan $M$ digunakan untuk menduga kematian kepiting bakau akibat penangkapan (F) dengan menggunakan persamaan sebagai berikut: 
$E=\frac{F}{F+M}$ atau $E=\frac{F}{Z}$

dimana : $\mathrm{Z}=$ total laju mortalitas (per tahun), $\mathrm{M}$ = laju mortalitas alami (per tahun), $\quad \mathrm{F}=$ laju mortalitas penangkapan (per tahun), $\mathrm{E}=$ laju eksploitasi (pertahun).

\section{HASIL DAN PEMBAHASAN}

\subsection{Struktur Ukuran}

Pengambilan sampel kepiting bakau

(Scylla serrata) dalam penelitian ini selama

4 bulan (Februari - Mei 2015) sebanyak 680

kepiting jantan dan 541 kepiting betina. Lebar

karapas/carapace width (CW) kepiting bakau yang tertangkap di Teluk Bintan berkisar dari 64 - $172 \mathrm{~mm}$ (jantan) dan 67 - $166 \mathrm{~mm}$ (betina) dengan bobot terbesar masing-masing $1.470 \mathrm{gr}$ dan 810 gram. Rata-rata CW jantan lebih besar dari betina dimana rata-rata $\mathrm{CW}$ jantan sebesar $121,81 \pm 21,45$ dan $118,28 \pm 23,28$ (betina), namun selisih standar deviasinya relatif kecil. Rata-rata bobot kepiting 494,5 $\pm 282,258$ gr (jantan) dan $353,71 \pm 172,61$ gr (Tabel 1), yang memiliki perbedaan standar deviasi antara jantan dan betina relatif besar. Ini berarti kepiting jatang memiliki kisaran rata-rata berat yang lebih besar.

Tabel 1 Ukuran lebar karapas dan bobot kepiting bakau di Teluk Bintan

\begin{tabular}{|l|c|c|c|c|c|c|c|}
\hline \multirow{2}{*}{ Jenis } & \multirow{2}{*}{$\mathrm{N}$} & \multicolumn{3}{|c|}{ Lebar Karapas/CW (mm) } & \multicolumn{3}{|c|}{ Bobot individu (gr) } \\
\cline { 3 - 8 } & & Min & Max & Rata-rata & Min & Max & Rata-rata \\
\hline Jantan & 680 & 64 & 172 & $121,81 \pm 21,45$ & 70 & 1.470 & $494,5 \pm 282,258$ \\
\hline Betina & 541 & 67 & 166 & $118,28 \pm 23,28$ & 60 & 810 & $353,71 \pm 172,61$ \\
\hline
\end{tabular}

Sumber : Hasil penelitian (2015)

Ukuran lebar karapas kepiting bakau yang ditemukan di Teluk Bintan lebih besar jika dibandingkan dengan kepiting bakau di Kutai Timur, dimana CW kepiting bakau terbesar yang tertangkap $154 \mathrm{~mm}$ (jantan) dan betina $155 \mathrm{~mm}$ (betina) Wijaya (2010), dan lebih kecil dari kepiting yang tertangkap di Teluk Lawele Sulawesi Tenggara yaitu mencapai $212,45 \mathrm{~mm}$ dengan berat 1.550 gr (betina) dan $210 \mathrm{~mm}$ dengan berat badan 1.700 gr (jantan) La Sara (2010). Kepiting bakau dari tiga lokasi di Indonesia lebih kecil dari Australia yang dapat mencapai ukuran CW $300 \mathrm{~mm}$ dan berat $2,5 \mathrm{~kg}$ (Departement of Fisheries Australia 2013).

Distribusi frekuensi ukuran lebar karapas/carapace width (CW) kepiting bakau yang tertangkap di Teluk Bintan yang didistribusikan dengan interval 10 dan 11 jumlah kelas disajikan pada Gambar 2. Ilustrasi menunjukkan bahwa distribusi frekuensi ukuran CW yang paling banyak tertangkap adalah ukuran 124-133 mm (jantan) dan 134-143 mm (betina).

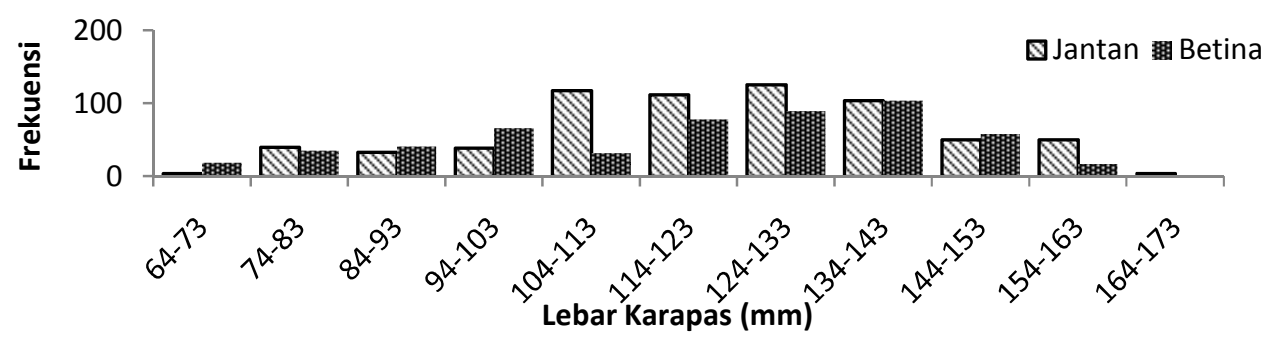

Gambar 2 Frekuensi lebar karapas Scylla serrata jantan dan betina di Teluk Bintan 
Distribusi frekuensi ukuran lebar diklasifikasikan berdasarkan tiga fase, yaitu juvenil, muda dan dewasa. Menurut La Sara (2010) Scylla serrata pada fase juvenil memiliki lebar karapas <70 $\mathrm{mm}$, fase muda (lebar karapas dari $70-<120$ $\mathrm{mm}$ ) dan fase dewasa (lebar karapas $>120 \mathrm{~mm}$ ). Menurut Bonine et al. (2008) kepitng bakau (Scylla serrata) jantan dewasa kelamin rata-rata ketika lebar karapas mulai ukuran 90-110, sedangkan kepitng betina mulai matang gonad pada rata-rata ukuran lebar karapas 80-120 mm. Ilustrasi distribusi frekuensi lebar karapas kepiting bakau di Teluk Bintan disajikan pada Gambar 3.

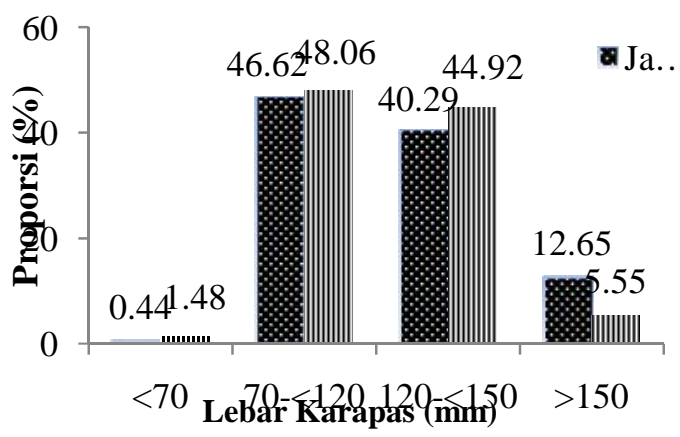

Gambar 3 Distribusi frekuensi lebar karapas Scylla serrat jantan dan betina

berdasarkan fase dan ukuran yang boleh diperdagangkan

Histogram di atas menunjukkan, kepiting bakau (Scylla serrata) jantan yang tertangkap di Teluk Bintan pada fase dewasa mencapai 52,94\% dan betina 50,46\% dengan kisaran lebar karapas masing-masing >120 - $172 \mathrm{~mm}$ dan >120-166 mm. Kepiting muda jantan yang tertangkap mencapai 46,62\% dan betina mencapai 48,06\% . Perbedaan jumlah individu kepiting dewasa dan kepiting muda jantan maupun betina yang tertangkap relatif kecil yaitu $6,32 \%$ dan $2,4 \%$. Sedangkan individu juvenil yang tertangkap hanya sebagian kecil yaitu di bawah $1,5 \%$.

Kepiting muda yang tertangkap di Teluk Bintan hampir separuh dari kepiting dewasa, ini menunjukkan bahwa alat tangkap yang digunakan belum selektif dan dapat berimplikasi terganggunya kemampuan rekrutmen dan tangkap lebih atau over eksploitasi. Selain itu, kepiting bakau fase juvenil yang tertangkap meskipun relatif kecil yaitu di bawah $1,5 \%$, ini juga menunjukkan alat tangkap yang digunakan belum selektif. Berdasarkan observasi di lapangan selama 4 bulan melakukan penelitian, belum pernah mendapatkan tangkapan kepiting yang sedang bertelur. Hal ini diduga disebabkan oleh pola penangkapan nelayan yang sebagian besar memasang alat tangkap di tengah hutan mangrove, di suak (cabang anak sungai) dan pinggiran sungai yang bukan merupakan tempat utama nelayan setempat menangkap kepiting, sedangkan kepiting betina yang matang gonad lebih banyak terdistribusi di bagian pantai atau mangrove dekat muara sunagi. Sejalan dengan hasil penelitian Wijaya (2010), kepiting betian matang gonad lebih banyak terditribusi di bagian muara yang merupakan pintu keluar dan masuk kepiting yang sedang bermigrasi dari perairan laut ke kawasan mangrove atau sebaliknya. Pola penangkapan seperti ini berdampak positif, karena dapat mengurangi tekanan pada kepiting yang matang gonad yang akan masuk ke ekosistem mangrove atau yang telah melakukan perkawinan dan bermigrasi ke perairan laut yang lebih dalam untuk menetaskan telurnya.

Sebagai perbandingan, kepiting yang tertangkap dengan bubu di Teluk Lawele Sulawesi Tenggara tidak tertangkap ukuran juvenil, pada kepiting muda hanya tertangkap sebanyak 9,5\%, sedangkan pada kepiting dewasa mencapai 90,5\% (La Sara 2010) Hal tersebut menunjukan bahwa bubu yang digunakan untuk menangkap kepiting di Teluk Lawele sangat selektif, sedangkan di Teluk Bintan belum. Oleh karenanya, alat tangkap yang dioperasikan di Teluk Bintan perlu di desain atau dimodifikasi lagi agar lebih selektif dan mampu mendapatkan hasil tangkapan kepiting yang telah dewasa. Alat tangkap sebaiknya di desain dengan kisaran tangkapan ukuran $>80 \mathrm{~mm}$ dengan tujuan penggunaan alat tangkap yang mendukung pengelolaan sumber daya kepiting yang berkelanjutan.

Usaha pengaturan penggunaan alat tangkap telah diterapkan di beberapa tempat seperti di Tanzania, dimana nelayan telah mampu menangkap kepiting bakau dari alam yang berukuran terkecil memiliki lebar karapas 120 mm dengan berat > $300 \mathrm{~g}$ (Moksnes, 2002). Australia juga melakukan strategi pengelolaan kepiting bakau dengan pengaturan alat tangkap, dan telah berhasil menaikkan ukuran tangkapan dari CW $130 \mathrm{~mm}$ ke $140 \mathrm{~mm}$ dengan proporsi mencapai lebih $70 \%$, sehingga kepiting betina 
terhidar dari kematian akibat penangkapan langsung dan mereka dapat hidup sampai tingkat kematangan gonad (Meynecke 2009).

Gambar 3 di atas juga menunjukkan kepiting yang memiliki frekuensi ukuran CW $>150 \mathrm{~mm}$, dimana kepiting bakau hasil tangkapan nelayan di Teluk Bintan yang memiliki ukuran tersebut sebesar 12,65\% (jantan) dan 5,55\% (betina). Ukuran CW >150 mm merupakan ukuran yang diizinkan untuk diperdagangkan oleh pemerintah Indonesia berdasarkan Peraturan Menteri Kelautan dan Perikanan RI (PermenKP No.1 2015). Patokan harga yang berlaku secara umum berdasarkan ukuran berat kepiting, begitu juga di Teluk Bintan. Level harga di lokasi penelitian ada empat kelas berdasarkan berat. Kelas pertama adalah >900 gr berat badan (setara dengan ukuran lebar karapas jantan >148,75 $\mathrm{mm}$ dan betina $>162 \mathrm{~mm}$ ) dengan harga Rp.120.000$130.000 / \mathrm{kg}$, kelas kedua 600-800 gr (CW jantan $>132-144 \mathrm{~mm}$ dan betina $>141-156 \mathrm{~mm}$ ) dengan harga Rp.100.000-110.000/kg, kelas ketiga 300500 gr (CW jantan >110-125 $\mathrm{mm}$ dan betina $>112-133 \mathrm{~mm}$ ) dengan Rp.80.000-Rp.90.000/kg, dan kelas keempat 100-200 gr (CW jantan >65$95 \mathrm{~mm}$ dan betina $>75-100 \mathrm{~mm}$ ) dengan harga Rp.30.000-50.000/kg. Sedangkan <100 gram harganya sangat rendah $(<25000 / \mathrm{kg})$.

Tingkatan harga kepiting berdasarkan ukuran berat juga berlaku di Berau Kalimantan Timur, sebagaimana diungkapkan oleh Sutrisno et al. (2014), harga kepiting berdasarkan ukuran berat dibagi atas tiga tingkatan yaitu dibawah 300 gr, 300-700 gr, dan diatas 700 gr. Begitu pula di Sulawesi Selatan (La Sara 2010), harga kepiting dikelompokkan dalam tiga kelas. Kelas satu, ukuran >800 gr, kelas dua, ukuran 500-800 gr dan kelas ketiga, ukuran $<500$ gr. Ukuran yang umum digunakan dipasaran adalah ukuran berat bukan ukuran lebar karapas.

\subsection{Upaya Tangkap dan Hasil Tangkapan}

Lokasi penangkapan kepiting bakau (Scylla serrata) di kawasan mangrove Teluk Bintan tersebar di kawasan ekosistem mangrove Tembeling, Bintan Buyu dan Penaga. Jumlah nelayan yang menangkap kepiting bakau di lokasi tersebut sebanyak 38 nelayan yang berasal dari masyarakat setempat. Dari jumlah tersebut, ada sebagian nelayan menangkap kepiting merupakan pekerjaan paruh waktu dengan pekerjaan lainnya seperti menangkap ikan, udang, rajungan, mencari kayu bakar dan hasil ekosistem mangrove lainnya. Produksi kepiting bakau hasil tangkapan nelayan belum terdata. Pendaratan hasil tangkapan kepiting bakau di lokasi penelitian tidak berada pada satu lokasi sehingga pendataan produksi kepiting hasil tangkapan total nelayan sulit untuk diperkirakan.

Data upaya dan hasil tangkapan kepiting bakau sangat penting untuk studi dinamika populasi. Meskipun S.serrata merupakan komoditi hasil perikanan yang memiliki nilai ekonomi penting, namun belum ada upaya yang dilakukan untuk mengumpulkan data dan informasi secara kontiniu tentang kepiting bakau hampir diseluruh wilayah di Indonesia (La Sara 2010). Upaya penangkapan kepiting bakau di Teluk Bintan umumnya menggunakan bubu injab dan bubu lipat, sangat jarang nelayan menggunakan alat pengait. Injab merupakan sebutan masyarakat lokal untuk alat tangkap bubu yang terbuat dari bambu berbentuk bulat panjang yang memiliki spesifikasi panjang (P) 80 $\mathrm{cm}$, diameter (D) $28 \mathrm{~cm}$, sedangkan bubu lipat merupakan bubu yang umum ada dipasaran yang memiliki spsesifikasi $55 \mathrm{~cm}$ x $40 \mathrm{~cm}$ x $20 \mathrm{~cm}$ dengan mesh size $2,5 \mathrm{~cm}$. Alat tangkap yang digunakan belum didesain secara khusus untuk menangkap kepiting bakau ukuran dewasa, seperti dengan cara memberi celah pelolosan pada bubu, sebagai mana dinyatakan oleh Boutson et al. (2009); Susanto dan Irnawati (2012) yang mengemukakan bahwa celah pelolosan yang dibuat pada bubu mampu meloloskan kepiting ukuran $<70 \mathrm{~mm}$ hingga $70 \%$ (hasil uji coba skala laboratorium.

Upaya penangkapan kepiting bakau di Teluk Bintan dilakukan sepanjang tahun dengan musim puncak berkisar pada bulan Oktober November, musim paceklik berkisar dari bulan April-Juni, sedangkan bulan lainnya rata-rata dalam kondisi sedang. Hasil wawancara terhadap 23 nelayan kepiting, upaya penangkapan kepiting bakau berkisar 15 - 26 hari/bulan dengan ratarata $19 \pm 4$ hari/bulan. Hasil tangkapan pada musim puncak rata-rata mencapai $40,63 \pm 18,68$ $\mathrm{kg} / \mathrm{bulan}$, musim sedang rata-rata $25,14 \pm 21,07$ $\mathrm{kg} /$ bulan dan hasil tangkapan nelayan musim paceklik rata-rata $13,13 \pm 9,38 \mathrm{~kg} /$ bulan (Gambar 4). 
Ketika pada musim paceklik dan hasil tangkapan menurun, mayoritas nelayan bergeser melakukan aktivitas lain seperti menangkap udang, ikan, mencari kayu dan hasil hutan lainya. Kebiasaan ini secara langsung dapat mengurangi tekanan terhadap penangkapan kepiting dan waktu jeda ini memberikan kesempatan kepada kepiting untuk melakukan rekrutmen. Menurut La Sara (2010) mengungkapkan bahwa nelayan di Teluk Lawele, pada musim paceklik mereka melakukan penangkapan spesies lain seperti menangkap tuna, mackarel dan hiu, sehingga tinggal sebagian kecil nelayan yang mencari kepiting bakau.

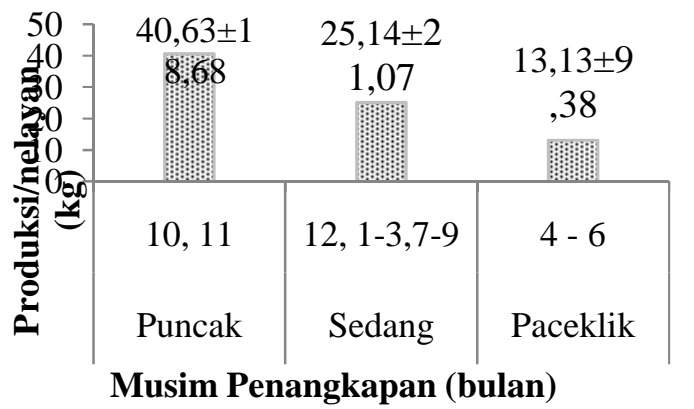

Gambar 4 Perbandingan hasil tangkapan kepiting bakau permusim di Teluk Bintan

\subsection{Hubungan Panjang Bobot Kepiting Bakau}

Pola pertumbuhan kepiting bakau (Scylla serrata) dianalisa menggunakan metode regresi dengan melihat hubungan antara lebar karapas dengan bobot tubuhnya. Hasil analisis menunjukkan nilai koefesien determinasi $\left(\mathrm{R}^{2}\right)$ kepiting bakau jantan sebesar 97,07\% dan betina $97,33 \%$ (Tabel 2) . $\mathrm{R}^{2}$ merupakan koefesien yang menjelaskan seberapa besar kemampuan variabel bebas $(\mathrm{X})$ mampu menjelaskan variabel terikat (Y), sehingga dapat ditentukan apakah individu dalam populasi dapat diduga bobot tubuhnya dengan mengetahui ukuran tubuhnya. Nilai $\mathrm{R}^{2}$ kedua jenis kelamin kepiting bakau tersebut menunjukkan bahwa bobot tubuh kepiting bakau di Teluk Bintan dapat di duga dari lebar karapasnya. Hasil analisis hubungan panjang bobot Scylla serrata jantan di diperoleh persamaan $\mathrm{W}=0,00007 L^{3,27724}$ dan $\mathrm{W}=0,0004 L^{2,8711}$ untuk kepiting betina sebagaimana dapat dilihat pada grafik hubungan panjang bobot pada Gambar 5 .

Tabel 2 Hubungan lebar karapas(CW) dan bobot kepiting bakau (Scylla spp.)

\begin{tabular}{|l|l|l|l|l|l|l|l|}
\hline \multicolumn{1}{|l|}{$\mathrm{W}=\mathrm{a} \mathrm{L}^{\mathrm{b}}$} & $\mathrm{N}$ & CWmax & $\mathrm{a}$ & $\mathrm{b}$ & $\mathrm{R}^{2}$ & Thit & Ttab \\
\hline Sex & 680 & 172 & 0,00007 & 3,2724 & 0,9707 & 154,8103 & 2,2464 \\
\hline Jantan & 541 & 166 & 0,0004 & 2,8711 & 0,9733 & 140,0930 & 1,9644 \\
\hline Betina & & & &
\end{tabular}

Sumber : Hasil olah penenlitian (2015)
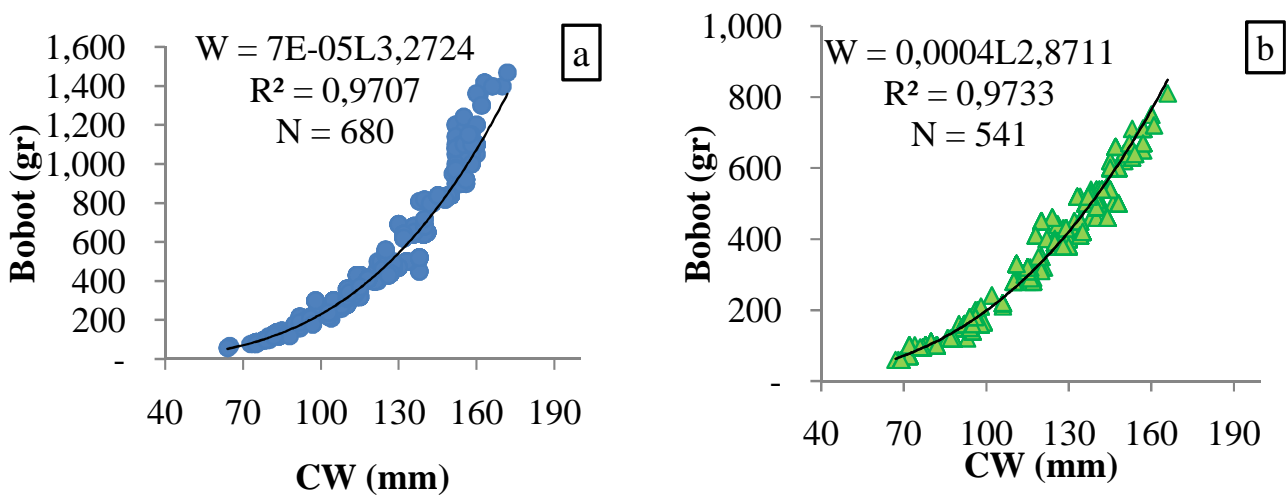

Gambar 5 Hubungan CW- bobot S.serrata (a) jantan (b) betina di Teluk Bintan 
Hasil uji $\mathrm{t}$ dari hubungan $\mathrm{CW}$ dengan bobot tubuh Scylla serrata baik jantan maupun betina menunjukkan hasil $t_{\text {hit }}$ lebih besar dari $t_{\text {tab, }}$ sehingga dapat dikatakan bahwa hubungan antara lebar karapas $(\mathrm{CW})$ dengan bobot kepiting tidak isometrik. Nilai b $S$. serrata diperoleh nilai b $>3$, berarti konstanta pertumbuhan kepiting bakau di wilayah tersebut adalah allometrik positif, atau dapat dikatakan pertumbuhan bobot tubuh lebih cepat daripada pertumbuhan CW. Sedangkan pada $S$. serrata betina, nilai b $<3$ berarti pola pertumbuhan pertumbuhannya adalah allometrik negatif, atau pertumbuhan bobot tubuh lebih lambat daripada pertumbuhan CW. Hal ini terjadi karena $S$. serrata. jantan memiliki morfologi ukuran chela yang lebih besar dibanding betina. Sehingga bila berada pada ukuran lebar karapas yang sama, kecenderungan kepiting jantan lebih berat bobotnya, karena chela menambah bobot tubuhnya (Wijaya, 2010).

\section{Menurut Siahainenia}

menunjukkan S.serrata memiliki sifat seksualitas dimorfisme, dimana kepiting jantan cenderung menjadi lebih berat dibanding kepiting betina pada lebar karapas yang sama. Selain itu, S.serrata jantan berukuran dewasa kelamin sudah jarang melakukan moulting dibanding dengan kepiting betina. frekuensi moulting yang rendah pada kepiting jantan, asupan makanan lebih banyak digunakan untuk pertambahan bobot. Kepiting bakau jantan biasanya memiliki capit lebih besar dibandingkan dengan betina dengan ukuran lebar carapas yang sama, bila berada pada ukuran lebar karapas yang sama, kecenderungan S.serrata jantan lebih besar bobotnya, karena capitnya menambah bobot tubuhnya Onyango (2002). Ukuran capit yang besar pada kepiting bakau jantan dewasa kelamin sangat berfungsi ketika mendekap atau mengepit kepiting bakau betina selama masa percumbuan yakni ketika kedua individu kepiting bakau ini berada dalam posisi berpasangan (doublers), serta untuk membalik tubuh kepiting bakau betina ketika proses kopulasi akan berlangsung (Phelan and Grubert 2007).

\subsection{Parameter Pertumbuhan}

Jumlah sampel kepiting bakau (Scylla serrata) yang digunakan dalam analisis parameter pertumbuhan ini sebayak 680 ekor jantan dan 541 ekor betina dan dilakukan pengelempokan berdasarkan distribusi fekuensi ukuran lebar carapas (CW). Pendugaan parameter pertumbuhan dalam penelitin ini menggunakan persamaan von Bertalanffy untuk menduga koefesien pertumbuhan $(\mathrm{K})$ dan lebar karapas infinitif $(\mathrm{CW} \infty)$ dengan data frekuensi lebar karapas sebagai data input pada analisis ELEFAN I (Electronic Length Frequencys Analysis) yang terdapat dalam program FISAT II. Hasil analisis parameter pertumbuhan kepiting bakau di Teluk Bintan menunjukkan bahwa $\mathrm{CW} \infty$ jantan lebih besar dari kepiting betina, namun sebaliknya nilai koofesien $\mathrm{K}$ jantan lebih kecil dari betina (Tabel 4).

Tabel 3 Parameter pertumbuhan S.serrata di Teluk Bintan

\begin{tabular}{|l|c|c|c|c|}
\hline \multicolumn{1}{|c|}{ Jenis Kelamin } & Cwmax $(\mathrm{mm})$ & $\mathrm{CW} \infty(\mathrm{mm})$ & $\mathrm{K}$ & $\mathrm{t} 0$ \\
\hline Jantan & 172 & 176,93 & 0,360 & $-0,2817$ \\
\hline Betina & 166 & 169,58 & 0,390 & $-0,2623$ \\
\hline
\end{tabular}

Sumber : Hasil penelitian (2015)

Kepiting bakau merupakan salah satu spesies dari kelas Crustacea, keberadaannya di alam sulit untuk ditentukan tingkat pertumbuhan yang benar, karena hewan ini mengalami moulting (Zafar et al. 2006). Sebagian besar studi tentang pertumbuhan telah dibuat pada Crustasea dengan cara dipelihara dalam bak atau sistem budidaya kandang/pen (Mirera and Milte 2009). Zafar et al. (2006) melaporkan bahwa kepiting bakau $S$. serrata berhasil di budidayakan di tambak tanah dan kandang di wilayah pesisir Bangladesh yang benihnya bersumber dari alam, kemudian dilakukan pendugaan pertumbuhan dengan menggunakan metode ELEFAN sehingga diperoleh nilai $\mathrm{CW} \infty$ sebesar 10,59 (jantan) dan 10,5 (betina).

Seperti terlihat pada Tabel 3, pertumbuhan kepiting bakau betina lebih cepat dari jantan, penelitian ini sejalan dengan hasil penelitian 
Wijaya (2010) di Muara Sangata Kutai Timur yang menyatakan nilai $\mathrm{K}$ jantan lebih besar dari betina yaitu 1,2 (jantan) dan 1,5 (betian), sedangkan Zafar et al.(2006) di Banglades melaporkan bahwa nilai $\mathrm{K}$ sebesar 0,28/tahun (jantan) dan 0,36/tahun (betina). Kedua penelitian tersebut menunjunkan bahwa kepiting betina tumbuh lebih cepat dari kepiting jantan. Menurut Sparre dan Venema (1999) niali koefesien K merupakan penentu seberapa cepat pertambahan ikan mencapai panjang asimtotiknya $(\mathrm{L} \infty)$. Perbedaan nilai koefesien $\mathrm{K}$ antara jenis kelamin mungkin bisa menjelaskan perbedaan dalam rasio jenis kelamin (La Sara 2010). Kecepatan pertumbuhan kepiting betina lebih cepat dari kepiting jantan karena kepiting betina lebih sering melakukan moulting dibanding kepiting jantan, sehingga kepiting betina cendrung lebih cepat mencapai $\mathrm{CW} \infty$, perbedaan nilai parameter pertumbuhan juga dipengaruhi perbedaan kualitas lingkungan habitat (Wijaya 2010).

Nilai parameter pertumbuhan berbedabeda menurut wilayah, karena faktor lingkungan seperti ketersediaan pangan, suhu air, salinitas, dan kualitas habitat. Misalnya, kepiting bakau dapat mentolerir suhu dalam kisaran yang luas yaitu suhu $12-35^{\circ} \mathrm{C}$ (eurythermal) dan salinitas 2-50 ppt (euryhaline) namun kepiting akan tumbuh optimal jika berada pada suhu yang sesuai (Masterson 2007). Telah ditemukan bahwa aktivitas makan kepiting bakau sangat lambat jika suhu berada bawah $20^{\circ} \mathrm{C}$ (Departement of Primery Industry and Fisheries, 2001). Menurut Shelley and Lovatelli (2011), temperatur yang sesuai untuk menunjang pertumbuhan optimal kepiting bakau jenis $S$. serrata yaitu kisaran $28-30^{\circ} \mathrm{C}$, sedangkan untuk keperluan kultur larva kepiting bakau dibutuhkan kisaran temperatur sebesar $25-32^{\circ} \mathrm{C}$.

\subsection{Laju Mortalitas}

Laju mortalitas dapat menunjukkan jumlah individu dalam populasi yang mati selama periode waktu tertentu, sedangkan laju eksploitasi merupakan suatu populasi tertentu yang telah tertangkap. Estimasi laju mortalitas (Z) dihitung dengan menggunakan kurva panjang-dikonversi dengan asumsi keadaan populasi tetap. Hasil estimasi Z kepiting bakau (Scylla serrata) jantan di Teluk Bintan lebih tinggi dari betina (Tabel 4). Berbeda dengan hasil perkiraan kematian alami (M) yang menggunakan persamaan empiris Pauly (dengan suhu rata-rata di loaksi penelitian sebesar $27.94^{\circ} \mathrm{C}$ ), hasil analisis menunjukkan bahwa $\mathrm{M}$ kepiting jantan mencapai $46,38 \%$ dari $\mathrm{Z}$, berarti kematian kepiting jantan di lokasi penelitian lebih besar kematian akibat penangkapan $(F)$. Sedangkan nilai $\mathrm{M}$ kepiting betina mencapai $58,77 \%$ atau lebih separuh dari nilai $\mathrm{Z}$, ini artinya laju mortalitas total lebih banyak disebabkan oleh kematian alami (Tabel 4).

Tabel 4 Total mortalitas (Z) dan mortalitas alami (M) Scylla serrata di Teluk Bintan

\begin{tabular}{|c|r|r|r|r|}
\hline Jenis Kelamin & \multicolumn{1}{|c|}{ Z } & M & F & \multicolumn{1}{|c|}{ E faktual } \\
\hline Jantan & 1,20 & 0,55661 & 0,6434 & 0,5362 \\
\hline Betina & 1,01 & 0,59353 & 0,4165 & 0,4123 \\
\hline
\end{tabular}

Sumber : Hasil olah penelitian (2015)

Laju eksploitasi (E) kepiting bakau di Teluk Bintan untuk kepiting jantan mencapai 53,62\%, ini dapat dikatakan telah terjadi lebih tangkap atau over eksploitasi karena nilai $\mathrm{E}>50 \%$. Sedangkan laju eksploitasi kepiting betina sebesar $41,23 \%$, berarti masih dibawah laju eksploitasi optimal yang diperbolehkan $(\mathrm{E}<50 \%)$. Menurut Mirera (2011), bahwa dalam dekade terakhir kegiatan ekploitasi terhadap kepiting bakau di alam meningkat disamping besarnya tekanan terhadap ekosistem mangrove, permasalahan ini dapat mengancam keberlanjutan perikanan tangkap dan di Kenya telah terjadi penurunan hasil tangkapan secara konsisten dalam dua dekade terahir dan ukuran kepiting hasil tangkapan menurun yang sebelumnya memiliki berat rata-rata $1 \mathrm{~kg} / \mathrm{ekor}$, saat ini rata-ratanya hanya sekitar $0,5 \mathrm{~kg} / \mathrm{ekor}$.

Laju kematian kepiting jantan akibat penangkapan $(\mathrm{F})$ di Teluk Bintan lebih tinggi dari kepiting betina, ini lebih disebabkan oleh dua faktor. Faktor pertama adalah habit dari kepiting itu sendiri, dimana kepiting jantan lebih aktif mencari makan dibanding betina, kepiting jantan dewasa cenderung menetap di area hutan 
mangrove (Phelan and Grubert 2007) sehingga peluang untuk tertangkapnya lebih besar. Kepiting betina dalam siklus hidupnya memiliki pola migrasi saat akan menetas dan kepiting beruaya ke perairan laut yang lebih dalam yang memiliki salinitas lebih tinggi (Departemen of Fisheries Australia 2013) dan jika tidak ada nelayan yang menangkap di pesisir pantai, muara dan perairan dalam maka peluang tertangkapnya cendrung lebih kecil. Sedangkan faktor kedua adalah pola penangkapan kepiting di lokasi kajian umumnya dilakukan di daerah pinggir aliran sungai, di dalam suak (cabang anak sungai), dan bagian tengah hutan mangrove dengan alat tangkap bubu. Tidak ada yang secara khusus nelayan setempat melakukan penangkapan kepiting di muara sungai, perairan pantai dan perairan yang lebih dalam.

Keadaan yang sama terjadi di Teluk Lawele, kematian akibat pengakapan (F) jantan mencapai mencapai $32,61 \%$ sedangkan betina sekitar 29,64\%. Nilai $F$ jantan lebih tinggi, terutama disebabkan oleh siklus setelah kawin, kepiting betina bermigrasi ke laut untuk bertelur. Sedangkan kepiting jantan menetap di daerah intertidal yang datar atau air dangkal yang merupakan lokasi dengan intensitas penangkapan lebih tinggi (La Sara (2010). Begitu juga di Bantanyan Philipina, laju mortalitas jantan lebih besar diakibatkan oleh aktivitas penangkapan sehingga laju eksploitasinya (E) mencapai $57,17 \%$ dan 50,18\% pada kepiitng betina (Ingles 1996).

Banyak faktor dalam lingkungan perairan laut yang dapat mempengaruhi kemungkinan individu kepiting bertahan hidup dalam suatu populasi. Kondisi yang termasuk merugikan antara lain kekurangan makanan, kompetisi dan predasi. Oleh karena itu, pengetahuan tentang angka kematian total, komponen kegiatan penangkapan dan kematian alami, sangat penting dipahami untuk melihat dinamika populasi. Haddon et al. (2005) mencatat bahwa kematian ikan akibat eksploitasi sulit diperkirakan secara tepat. Kesulitan yang sama terkait dengan memperkirakan tingginya tingkat mortalitas total S.serrata meskipun memiliki nlai ekonomi penting, populasi yang dinamis masih kurang dipahami karena tidak ada informasi tentang kematian dan dilakukan penilaian stok di daerah tropis. Mengingat fakta ini, langkah-langkah penanganan harus diambil untuk memperkirakan kematian total populasi ikan.
Dugaan masyarakat terhadap menurunnya produksi hasil tangkapan kepiting bakau berdasarkan analisis laju mortalitas total menunjukkan bahwa laju eksploitasi kepiting jantan di Teluk Bintan telah terjadi over eksploitasi, sedangkan kepiting betina masih dibawah laju eksploitasi yang diperbolehkan. Menurut Triyanto et al. (2013) dan Siahainenia (2008) menurunya populasi kepiting bakau di alam dapat disebabkan oleh kerusakan ekosistem mangrove sebagai habitat alami kepiting bakau dan juga akibat kelebihan tangkap atau over eksploitasi. Menurut Keenan et al. (1998); Keenan (1999); LeVay (2001), kepiting bakau merupakan jenis kepiting yang hidup di habitat mangrove dan populasi kepiting bakau secara khas berasosiasi dengan hutan mangrove yang masih baik, sehingga terdegradasinya habitat akan memberikan dampak yang serius terhadap keberadaan populasi kepiting bakau.

\section{KESIMPULAN}

\section{Kesimpulan}

1. Kepiting jantan dan betina fase muda yang tertangkap hampir separuh dari total tangkapan yaitu 46,62\% (jantan) dan $48,06 \%$ (betina), yang berarti alat tangkap yang digunakan belum selektif dan akan manggangu kemampuan rekrutmen kepiting bakau.

2. Estimasi mortalitas alami (M) kepiting jantan sebesar 46,38\% dari Z, artinya kematian kepiting jantan lebih besar diakibatkan penangkapan. Sedangkan M kepiting betina mencapai $58,77 \%$ dari $\mathrm{Z}$, ini artinya laju mortalitas total lebih banyak disebabkan oleh kematian alami.

3. Laju eksploitasi (E) Scylla serrata jantan telah melebihi batas optimal yang diperbolehkan atau telah terjadi over eksploitasi ( $\mathrm{E}>50 \%)$, karena kepiting jantan lebih banyak menetap di area mangrove dan daerah intertidal dengan intensitas penangkapannya yang tinggi.

\section{Saran}

1. Perlu dilakukan rasionalisasi penggunaan alat tangkap kepiting bakau di lokasi penelitian, agar hasil tangkapan dapat dibatasi pada kelompok ukuran dewasa. 
2. Perlu dilakukan kajian jangkauan ruaya kepiting bakau di perairan Teluk Bintan dan sekitar pulau Bintan.

\section{DAFTAR PUSTAKA}

Bonine, K.M., E.P. Bjorkstedt, K.C. Ewel, and M. Palik. 2008. Population characteristics of the mangrove crab Scylla serrata (Decapoda: Portunidae) in Kosrae, Federated States of Micronesia: Effects of harvest and implications for management. Pacific Science 62: 1-19.

Boutson, A., C. Mahasawade, S. Mawasawade, S. Tunkijjanukij, and T. Arimoto. 2009. Use of Escape Vents to Improve Size and Species Selectivity of Collapsible Pot for Blue Swimming Crab Portunus Pelagicus in Thailand. Fisheries Science (75) : 25-33.

Department of Primary Industry and Fisheries. 2001. Review of the Northern Territory mud crab fishery management plan. Fish. Rep. No.58. Northern Territory.

Departement of Fisheries Australia. 2013. Fisheries fact shett mud crab. Fish for the future. Goverment of Western Australia.

Dumas, P., M. Leopold, L. Frotte, and C. Peignon. 2012. Mud crab ecology encourages site-specific approaches to fishery management. Journal of Sea Research 67: 1-9.

Effendie, M.I. 2006. Biologi perikanan. Yayasan Pustaka Nusatama. Yogyakarta.163 hal.

Haddon, M., S. Frusher, T. Hay, M. Hearnden, N. Gribble and I. Brown. 2005. Mud crab (Scylla serrata) assessment workshop. Fisheries Group. Department of Business. Industry and Resource Development. Darwin

[ITTO] International Tropical Timber Organization-Project. 2013. Study on socio-economic community-based mangrove ecosystem management at Bintan Regency Riau Islands Province. Kementerian Kehutanan RI.
Ingles, J.A. 1996. The crab fishery off Bantayan, Cebu, Philippines. IMFOCF, University of the Philippines PCMARD. Philippines.

Keenan, C.P. 1997. Aquaculture of the mud crab, genus Scylla, past, present and future. ACIAR Proceedings No.78. In: Keenan, C.P., Blackshaw, A. (Eds.), MudCrab Aquaculture and Biology, Proceedings of an International Scientific Forum, Darwin, Australia, 21-24 April 1997. Australian Centre for International Agricultural Research. Canberra. Australia. 9-13pp.

Keenan, C.P., P.J.F. Davie, and D.L. Mann. 1998. A revision of the genus Scylla De Haan, 1833 (Crustacea: Decapoda: Brachyura: Portunidae). The Raffles Bulletin of Zoology. 46 (1): 217-245.

[KKP] Kementrian Negara Kelautan dan Perikanan. 2015. Keputusan Nomor 1/Permen-kp/2015 tentang Penangkapan Lobster (Panulirus spp.), kepiting (Scylla spp.), dan rajungan (Portunus pelagicus spp.). KKP RI.

Larosa, R., B. Hendrarto, and M. Nitisupardjo. 2013. Identifikasi sumberdaya kepiting bakau (scylla sp.) yang didaratkan di TPI Kabupaten Tapanuli Tengah. Journal of management of aquatic resources. 2 (3):180-189.

La Sara. 2010. Studi on the size structure and population parameters of mud crab Scylla serrata in Lawele Bay, Southeast Sulawesi, Indonesia. Journal of Coastal Development. 13(2):133147.

LeVay, L. 2001. Ecology and management of the mud crab, Scylla spp. Asian Fisheries Science. 14:101-111.

Masterson, J. 2007. Scylla serrata. Smithsonian Marine Station at Fort Pierce.

Meynecke, J.O. 2009. Effect of climate parameters on mud crab (Scylla serrata) production in Australia. IOP Conf. Series: Earth and Env. Sci. 6: 1.

Mirera, D.O. and A. Mtile. 2009. A preliminary study on the response of 
mangrove mud crab (Scylla serrata) to different feed types under drive-in cage culture system. J. Ecol. Nat. Env. 1(1):7-14.

Mirera, D.O, J. Ochiewo, F. Munyi, and T. Muriuki. 2013. Heredity or traditional knowledge: Fishing tactics and dynamics of artisanal mangrove crab (Scylla serrata) fishery. Ocean \& Coastal Management. 84: 119-129.

Moksnes, P.O. 2002. The relative importance of habitat-specific settlement, predation and juvenile dispersal for distribution and abundance of young juvenile shore crab Carcinus maenas L. J. Exp. Mar. Biol. Ecol. 271:41-73.

Onyango, S.D. 2002. The breeding cycle of Scylla serrata (Forskål, 1755) at Ramisi River estuary, Kenya. Wetlands Ecology and Management 10: 257- 263.

Phelan, M., and M. Grubert. 2007. The Life Cycle of the Mud Crab. Fishnote No: 11. Coastal Research Unit, Department of Primary Industry, Fisheries and Mines. Northern Territory Government of Australia, Darwin.

Pauly, D. 1984. Fish Population Dynamics inTropical Water: a manual for use with programmable calculators. ICLARM Studies and Reviews. 325 p.

Siahainenia, L. 2008. Bioekologi kepiting bakau (Scylla spp) di ekosistem mangrove Kabupaten Subang Jawa Barat. [Disertasi]. Sekolah Pascasarjana IPB. Bogor.

Shelley, C. and A. Lovatelli. 2011. Mud Crab Aquaculture a Practical Manual FAO Fisheries and Aquaculture Technical Paper 567.

Sparre, P. and S.C. Venema. 1999. Introduksi Pengkajian Stok Ikan Tropis. Organisasi Pangan dan Pertanian (FAO), PBB. Edisi Bahasa Indonesia: Puslitbangkan. Indonesia.

Susanto dan Irnawati. 2012. Penggunaan celah pelolosan pada bubu lipat kepiting bakau (skala laboratorium). Jurnal Perikanan dan Kelautan. 2 (2): 71-78.
Sutrisno, A. Hamdani, and Triyanto. 2014. Budidaya kepiting bakau (Scylla serrata) dalam pemnafaatan kawasan mangrove di Kabupaten Berau Kalimantan Timur. Prosisding Semnas Limnologi VII-2014. Puslit LimnologiLIPI.

Triyanto, N.I. Wijaya, I. Yuniarti, T. Widianti, Sutrisno, F. Setiawan, F. S. Lestari. 2013. Peranan Ekologis Hutan Mangrove dalam Menunjang Produksi Kepiting Perikanan Bakau (Scylla serrata) di Kabupaten Berau. Prosiding.

Walpole, R.E. 1992. Pengantar Statistika. Edisi ke-3. B. Sumantri, penerjemah; Jakarta: Penerbit Gramedia Pustaka Utama. $488 \mathrm{hlm}$.

Wijaya, N.I, F. Yulianda, M. Boer, and S. Juwana. 2010. Biologi populasi kepiting bakau (scylla serrata) Di habitat mangrove taman nasional kutai kabupaten kutai timur. Oseanologi dan Limnologi di Indonesia. LIPI. 36(3): 443-461.

Wijaya, N.I. 2011. Pengelolaan Zona Pemanfaatan Ekosistem Mangrove Melalui Optimasi Pemanfaatan Sumberdaya Kepiting Bakau (Scylla serata) Di Taman Nasional Kutai Provinsi Kalimantan Timur (Disertasi). Program Pasca Sarjana. IPB. Bogor.

Zafar, M., S.M.N. Amin and M.M. Rahman. 2006. Population dynamics of mud crab (Scylla serrata) in the southern coastal region of Bangladesh. Asian Fish. Sci.19:43-50. 